\title{
Prevalence and Associated Factors of Pressure Ulcer among Hospitalized Patients at Felegehiwot Referral Hospital, Bahir Dar, Ethiopia
}

\author{
Haileyesus Gedamu, ${ }^{1}$ Mignote Hailu, ${ }^{2}$ and Abdella Amano ${ }^{3}$ \\ ${ }^{1}$ Department of Nursing, Debre Tabor University, Debre Tabor, Ethiopia \\ ${ }^{2}$ Department of Nursing, College of Medicine and Health Sciences, University of Gondar, P.O. Box 196, Gondar, Ethiopia \\ ${ }^{3}$ Department of Midwifery, College of Medicine and Health Sciences, University of Gondar, P.O. Box 196, Gondar, Ethiopia \\ Correspondence should be addressed to Haileyesus Gedamu; haileyesusg5@gmail.com
}

Received 17 August 2014; Revised 23 November 2014; Accepted 27 November 2014; Published 16 December 2014

Academic Editor: Violeta Lopez

Copyright (C) 2014 Haileyesus Gedamu et al. This is an open access article distributed under the Creative Commons Attribution License, which permits unrestricted use, distribution, and reproduction in any medium, provided the original work is properly cited.

\begin{abstract}
Introduction. Pressure ulcers, also known as decubitus ulcers (bed sores), are localized skin injuries that remain a major health problem affecting approximately 3 million adults. Objective. The aim of this study was to assess the prevalence and associated factors of pressure ulcer among hospitalized patients in Felegehiwot referral hospital. Methods. This cross-sectional study used systematic sampling on a sample of 422 patients. The data was collected by trained data collectors through pretested checklist. Bivariate analysis was used principally and variables were then entered into multiple logistic regressions model for controlling the possible effect of confounders and the variables which have significant association were identified on the basis of OR with $95 \%$ CI and $P$ value. Results. The finding of this study revealed that $71(16.8 \%)$ of them had pressure ulcer. Prolonged length of stay in hospital, slight limit of sensory perception, and friction and shearing forces were significantly associated with the presence of pressure ulcer. Conclusions and Recommendations. The prevalence of pressure ulcer was high among hospitalized patients. Researches of prospective (followup) study required investigating the incidence and associated factors of pressure ulcer for hospitalized patients.
\end{abstract}

\section{Background}

Pressure ulcers also known as decubitus ulcers (bed sores) are localized skin injuries that develop when soft tissue is compressed between a bony prominence and an external surface for a prolonged period of time. It leads to ischemia, cell death, and tissue necrosis, as capillaries are compressed and the blood flow is restricted $[1,2]$. The cutaneous tissues become broken or destroyed, leading to progressive destruction and necrosis of underlying soft tissues. This process results in a painful and slow healing of pressure ulcer. Pressure ulcers are usually occurring over bony prominences such as sacrum, shoulders, occiput, ear lobes, elbows, and trochanters depending on patients' position $[3,4]$.

The most important cause of pressure ulcers is pressure exerted for an excessive period of time. Other physical influences that can damage the skin include friction at the skin surface, shearing forces (lateral displacement of the skin, whose layers are of differing firmness), and moisture. Moisture is also associated with the development of pressure ulcer. Loss of sensory perception (impaired level of consciousness) and immobility are the main risk factors for decubitus ulcers because patients may not be aware of the discomfort and do not change their position to relieve the pressure [5-7].

Development of pressure ulcers is complex and multifactorial. Despite advances in medical technology and the use of formalized prevention programs based on clinical practice guidelines, the prevalence of pressure ulcers during hospitalization continues to increase (80\%). Among all hospitalized patients, prevalence rates of acquired pressure ulcers are the highest in patients in the intensive care unit (ICU), from $14 \%$ to $42 \%$. Mortality is also associated with pressure ulcers. Several studies noted mortality rates as high as 60 percent for 
older persons with pressure ulcers within 1 year of hospital discharge $[8,9]$.

Preventing pressure ulcers can be nursing intensive. Studies have suggested that pressure ulcer development can be directly affected by the number of nurses and time spent at the bedside. The frequent assessment and effective skin care prevent the development of pressure ulcer [10]. Changing patients position every two hours and use of pressure relieving mattress also reduce developing of pressure ulcer because turning patients every 2 hours promotes comfort, reduces pressure, increases circulation, exercises joints, and promotes muscle tone $[1,11]$.

Once PU is developed, it can provide wound healing process by change of dressing, continued wound assessment, and proper nutrition. High protein diet was indicated because high amount of protein is lost through the wound. However the cost of treatment has been estimated as 2.5 times that of prevention; implementing a pressure ulcer prevention program remains essential. When the stage of PU increases, the cost of treatment also increases; as a result, stage IV of PU requires high cost [12-14]. So the purpose of this study was to assess the prevalence and associated factors of pressure ulcer among hospitalized patients in Felegehiwot referral hospital.

\section{Methods}

A community based cross-sectional study was conducted in Felegehiwot referral hospital, Bahir Dar, from March 25, 2013, to May 1, 2013. Bahir Dar is the capital city of Amhara region which is found $564 \mathrm{KM}$ away from Addis Ababa. Felegehiwot hospital is one of the referral hospitals in Amhara region. The hospital is expected to give service for five million people for the nearby zones and woreda people. This hospital has different wards. Among these wards medical ward, surgical ward, and gynecological wards are important to this research with the total bed number of 256, 84 from medical ward, 140 from surgical ward, and 32 from gynecological ward.

The source populations were all admitted patients in Felegehiwot referral hospital. And the study populations were those patients who have been admitted in medical, surgical, and gynecological wards in Felegehiwot referral hospital during study period. All admitted patients who were staying in hospital greater than or equal to 24 hours were included in the study. Those patients who have been admitted for the second time during data collection period and patients who developed pressure ulcer before admission in Felegehiwot referral hospital were excluded from the study.

The sample size was determined by using a single population proportion formula considering the following assumptions: prevalence $(p)$ of pressure ulcer $50 \%$ to get the lager sample size, $Z=$ standard normal distribution value at $95 \%$ confidence level of $\mathrm{Za} / 2=1.96$, and margin of error $(w)=5 \%$. This gave a sample size of 384 admitted patients. Adding a 10\% nonresponse rate, the total sample size was 422 . Final sample was selected based on bed number by systematic sampling technique from each ward. The first study unit was taken by lottery method.
Data was collected by face to face interviews using a structured and pretested questionnaire, prepared check lists, and physical examination. Four B.S. nurses were used to collect data. Two health officers were assigned to supervise the data collection process. Training was given for both data collectors and supervisors. Data entry was done by using EPI Info version 3.5.3 statistical software and exported to SPSS version 20.0 software package for analysis. The presence of association between independent and dependent variables was assessed using odds ratio with 95\% confidence interval by applying logistic regression model.

Ethical clearance was obtained from the Department of Nursing, University of Gondar. An official letter of cooperation was delivered to the administrations of the hospital. Study participants were given information about the fact that they have full right not to participate in the study if they were not willing. To ensure confidentiality anonymity was explained clearly to participants. Nursing care was given for those patients who have developed pressure ulcer during study period.

\section{Results}

3.1. Sociodemographic Characteristics. A total of 422 admitted patients in Felegehiwot referral hospital were included in this study with the response rate of $100 \%$. Overall, $57.3 \%$ (242) and $82.9 \%$ (350) respondents were rural residents and Orthodox Christianity followers, respectively. Proportion of females were $49.3 \%$ (208), the majority of the study participants were found in the age range of $18-32$ (50.2\%), and the median age of the respondents was 32 years (interquartile range $=24.5-45$ years). Majority of the respondents $(64.5 \%)$ were married and $18.5 \%$ (78) participants were single. About $36 \%$ (152) of the respondents were not educated and $12.1 \%$ (51) respondents completed grade 10 (Table 1).

3.2. Prevalence and Stages of Pressure Ulcer. A total of 71 pressure ulcers were detected in 422 patients, with the prevalence rate of $16.8 \%$. The prevalence of pressure ulcer was higher in male respondents (42) than in female respondents (29). Based on EPUAP grading scale, 62\% (44) and 26.8\% (19) patients developed stage I and stage II pressure ulcer, respectively. Among ulcer developed patients, $2.8 \%$ (2) constituted advanced stage (stage IV) of pressure ulcer. Of those who developed pressure ulcer, most of the participants $70.4 \%$ (50) developed sacral area and 10\% (7) patients developed pressure ulcer at both sacral and shoulder area (Figure 1).

\subsection{Length of Stay in Hospital and Change of Patients} Position. Almost half of admitted patients (49\%) in Felegehiwot referral hospital had 7-20 days length of stay in the hospital and $42.7 \%$ (180) patients were discharged before 7 days, whereas $8.3 \%$ (35) patients stayed in hospital for more than 20 days. The median hospital length of stay was 8 (interquartile range of 4-13) days. From the total individuals who developed pressure ulcer, $98.6 \%$ have not used pressure relieving device; however, only one patient applied air ring as pressure relieving device. Among the total pressure ulcer 
TABLE 1: Sociodemographic characteristics of the respondents who were admitted at Felegehiwot referral hospital, Bahir Dar, Ethiopia $(N=422)$.

\begin{tabular}{|c|c|c|}
\hline Variables & Frequency & Percent \\
\hline \multicolumn{3}{|l|}{ Age } \\
\hline $18-32$ & 212 & 50.2 \\
\hline $33-53$ & 135 & 32 \\
\hline$\geq 54$ & 75 & 17.8 \\
\hline \multicolumn{3}{|l|}{ Sex } \\
\hline Female & 208 & 49.3 \\
\hline Male & 214 & 50.7 \\
\hline \multicolumn{3}{|l|}{ Religion } \\
\hline Orthodox & 350 & 82.9 \\
\hline Muslim & 61 & 14.5 \\
\hline Protestant & 7 & 1.7 \\
\hline Others & 4 & 0.9 \\
\hline \multicolumn{3}{|l|}{ Place of residence } \\
\hline Urban & 180 & 42.7 \\
\hline Rural & 242 & 57.3 \\
\hline \multicolumn{3}{|l|}{ Marital status } \\
\hline Married & 272 & 64.5 \\
\hline Single & 78 & 18.5 \\
\hline Divorced & 45 & 10.7 \\
\hline Widowed & 27 & 6.4 \\
\hline \multicolumn{3}{|l|}{ Educational status } \\
\hline Not educated & 152 & 36 \\
\hline Read and write & 31 & 7.3 \\
\hline Grades 1-4 & 59 & 14 \\
\hline Grades 5-8 & 70 & 16.6 \\
\hline Grades 9-10 & 59 & 14 \\
\hline$\geq$ grade 11 & 51 & 12.1 \\
\hline
\end{tabular}

developed respondents 93\% (66) have not changed their position by nurses. Of patients' changed their position, $67.8 \%$ (40) changed their position every 2 to 3 hours, $10 \%$ (6) changed their position every 4 hours, and $8.6 \%$ (5) changed their position 4 times per day, whereas $13.6 \%$ (8) patients changed their position less than 4 times/days.

3.4. Factors Associated with Pressure Ulcer. Fourteen independent variables were analyzed in logistic regression with dependent variable of pressure ulcer to know their association. Those variables which were significant at $P \leq 0.2$ entered into multivariate logistic regressions. This multivariate analysis had identified that length of stay in hospital, sensory perception, and friction and shear had significant association with pressure ulcer. Those participants who had stayed in hospital $\geq 21$ days were 6 times (95\% CI: 2.55, 15.00) more likely to develop pressure ulcer than those participants who had stayed $\leq 6$ days. Participants who had slightly limited sensory perception were 3.3 times (95\% CI: 1.39, 7.75) at higher risk to develop pressure ulcer than those who had no

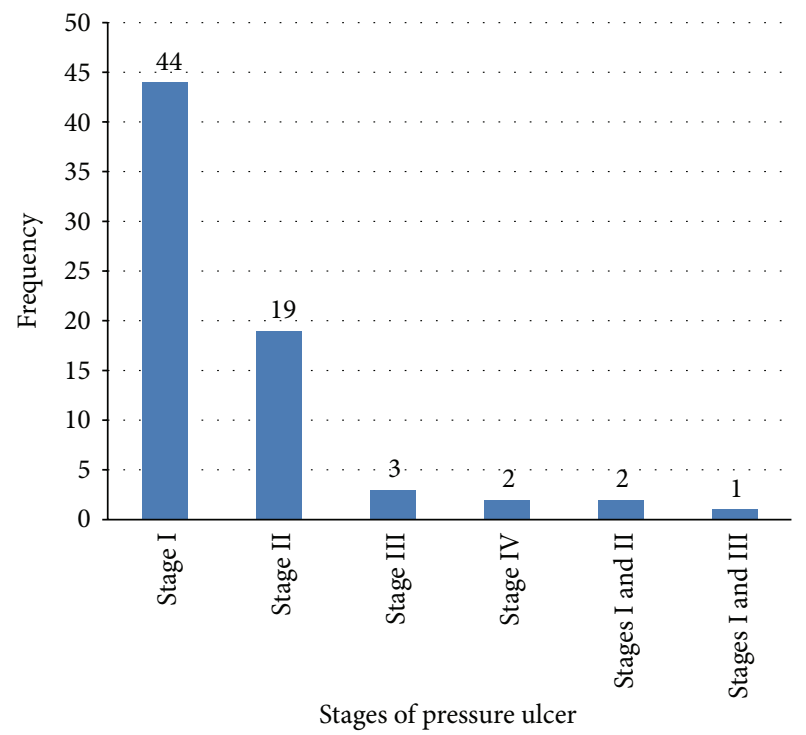

FIGURE 1: Stages of pressure ulcer in patients who were admitted at Felegehiwot referral hospital, Bahir Dar, 2013.

impairment in sensory perception. Those participants who had problem in friction and shearing forces were 4.5 times (95\% CI: 1.56, 12.93) more likely to develop pressure ulcer than those who had no apparent problem (Table 2).

\section{Discussion}

In this study, the prevalence of pressure ulcer was $16.8 \%$. This result was slightly higher than studies conducted in Brazil, Turkey, and Germany with prevalence of $12.7 \%, 10.4 \%$, and $11.7 \%$, respectively [15-17]. Higher prevalence in this study might be due to inappropriate nursing care and inadequate pressure relieving devices.

The prevalence rate lower than study conducted in Sweden (22.9\%), Italy (27\%), and Thailand (47.6\%) was also found [18-20]. This discrepancy might be due to different characteristics of participants, disease condition of patients, and the variation of length of stay in hospital.

The study showed that presence of pressure ulcer was significantly associated $(P<0.001)$ with the use of pressure ulcer preventive devices [21,22]; however, in this study $98.6 \%$ among pressure ulcer developed participants did not apply pressure relieving devices. The reason might be inadequacy of materials in the hospital or work overload of nurses in applying pressure relieving devices.

On this finding the age of the patient and length of stay in hospital were associated with the occurrence of pressure ulcer. As the age of the patient and length of stay in hospital increased, the development of pressure ulcer also increased. This finding was supported by the study conducted in Sweden; older age $(P=0.004)$ and more days of hospitalization $(P=0.001)$ were significantly associated with pressure ulcer [23]. Although age was predictor factor for pressure ulcer, it was not associated with the development of pressure ulcer in multiple logistic regressions in this study. 
TABLE 2: Association between some selected variables and pressure ulcer in Felegehiwot referral hospital, Bahir Dar, Ethiopia, 2013 ( $n=422$ ).

\begin{tabular}{|c|c|c|c|c|}
\hline \multirow{2}{*}{ Variables } & \multicolumn{2}{|c|}{ Pressure ulcer } & \multirow{2}{*}{$\begin{array}{c}\text { COR } \\
(95 \% \mathrm{CI})\end{array}$} & \multirow{2}{*}{$\begin{array}{l}\text { AOR } \\
(95 \%)\end{array}$} \\
\hline & Yes & No & & \\
\hline \multicolumn{5}{|l|}{ Age } \\
\hline 18-32 years & $30(14.2 \%)$ & $182(85.8 \%)$ & 1 & \\
\hline $33-53$ years & $24(17.8 \%)$ & $111(82.2 \%)$ & $1.310 .73,2.36)$ & \\
\hline$\geq 54$ years & $17(22.7 \%)$ & $58(77.3 \%)$ & $1.78(0.91,3.46)^{*}$ & \\
\hline \multicolumn{5}{|l|}{ Sex } \\
\hline Male & $42(19.6 \%)$ & $172(80.4 \%)$ & 1 & \\
\hline Female & $29(13.9 \%)$ & $179(86.1 \%)$ & $0.66(0.39,1.11)^{*}$ & \\
\hline \multicolumn{5}{|l|}{ Religion } \\
\hline Orthodox & $60(17.1 \%)$ & $290(82.9 \%)$ & 1 & \\
\hline Muslim & $8(13.1 \%)$ & $53(86.9 \%)$ & $0.73(0.33,1.61)$ & \\
\hline Protestant & $3(42.1 \%)$ & $4(57.1 \%)$ & $0.63(0.79,6.61)$ & \\
\hline Others & 0 & $4(100 \%)$ & $0.000(0.00)$ & \\
\hline \multicolumn{5}{|l|}{ Place of residence } \\
\hline Urban & $24(13.3 \%)$ & $156(86.7 \%)$ & 1 & \\
\hline Rural & $47(19.4 \%)$ & $195(80.6 \%)$ & $1.57(0.92,2.68)^{*}$ & \\
\hline \multicolumn{5}{|l|}{ Educational status } \\
\hline Illiterate & $34(22.4 \%)$ & $118(77.6 \%)$ & $2.16(0.85,5.51)^{*}$ & \\
\hline Read and write & $7(22.6 \%)$ & $24(77.4 \%)$ & $2.19(0.66,7.25)^{*}$ & \\
\hline Grades 1-4 & $6(10.2 \%)$ & $53(89.8 \%)$ & $0.85(0.26,2.82)$ & \\
\hline Grades 5-8 & $10(14.3 \%)$ & $60(85.7 \%)$ & $1.25(0.42,3.69)$ & \\
\hline Grades 9-10 & $8(13.6 \%)$ & $51(86.4 \%)$ & $1.18(0.38,3.65)$ & \\
\hline$>$ grade 10 & $6(11.8 \%)$ & $45(88.2 \%)$ & 1 & \\
\hline \multicolumn{5}{|l|}{ Marital status } \\
\hline Married & $43(15.8 \%)$ & $229(84.2 \%)$ & 1 & \\
\hline Single & $12(15.4 \%)$ & $66(84.6 \%)$ & $0.97(0.48,1.94)$ & \\
\hline Divorced & $7(15.6 \%)$ & $38(84.4 \%)$ & $0.98(0.41,2.34)$ & \\
\hline Widowed & $9(33.3 \%)$ & $18(66.7 \%)$ & $2.66(1.12,6.320)^{* *}$ & \\
\hline \multicolumn{5}{|l|}{ Length of stay } \\
\hline$\leq 6$ days & $14(7.8 \%)$ & $166(92.2 \%)$ & 1 & 1 \\
\hline $7-20$ days & $45(21.7 \%)$ & $162(78.3 \%)$ & $3.29(1.74,6.23)^{* *}$ & $3.71(1.8,7.9)$ \\
\hline$\geq 21$ days & $12(34.3 \%)$ & $23(65.7 \%)$ & $6.19(2.55,15.0)^{* *}$ & $5.97(1.98,18)$ \\
\hline \multicolumn{5}{|l|}{ Change of position } \\
\hline No & $66(18.2 \%)$ & $297(81.8 \%)$ & $2.40(0.92,6.23)^{*}$ & \\
\hline Yes & $5(8.5 \%)$ & $54(91.5 \%)$ & 1 & \\
\hline \multicolumn{5}{|l|}{ Sensory perception } \\
\hline Completely limited & $7(36.8 \%)$ & $12(63.2 \%)$ & $5.54(1.88,16.36)^{* *}$ & $1.39(0.36,5.32)$ \\
\hline Very limited & $18(22.8 \%)$ & $61(77.2 \%)$ & $2.8(1.31,6.00)^{* *}$ & $1.57(0.59,4.16)$ \\
\hline Slightly limited & $32(18.1 \%)$ & $145(81.9 \%)$ & $2.1(1.07,4.10)^{* *}$ & $3.29(1.39,7.75)$ \\
\hline No impairment & $14(9.5 \%)$ & $133(90.6 \%)$ & 1 & 1 \\
\hline \multicolumn{5}{|l|}{ Moisture } \\
\hline Constantly moist & $8(32 \%)$ & $17(68 \%)$ & $4.64(1.48,14.57)^{* *}$ & \\
\hline Very moist & $34(26.8 \%)$ & $93(73.2 \%)$ & $3.6(1.51,8.61)^{* *}$ & \\
\hline Occasionally moist & $22(11.3 \%)$ & $172(88.7 \%)$ & $1.26(0.52,3.09)$ & \\
\hline Rarely moist & $7(9.2 \%)$ & $69(90.8 \%)$ & 1 & \\
\hline \multicolumn{5}{|l|}{ Activity } \\
\hline Bedfast & $53(34.4 \%)$ & $101(65.6 \%)$ & $3.36(1.24,9.13)^{* *}$ & \\
\hline Chairfast & $8(6.4 \%)$ & $117(93.6 \%)$ & $0.44(0.13,1.43)^{*}$ & \\
\hline Walks occasionally & $5(4.7 \%)$ & $101(95.3 \%)$ & $0.32(0.09,1.17)^{*}$ & \\
\hline Walks frequently & $5(13.5 \%)$ & $32(86.5 \%)$ & 1 & \\
\hline
\end{tabular}


TABLE 2: Continued.

\begin{tabular}{|c|c|c|c|c|}
\hline \multirow{2}{*}{ Variables } & \multicolumn{2}{|c|}{ Pressure ulcer } & \multirow{2}{*}{$\begin{array}{c}\text { COR } \\
(95 \% \mathrm{CI})\end{array}$} & \multirow{2}{*}{$\begin{array}{c}\text { AOR } \\
(95 \%)\end{array}$} \\
\hline & Yes & No & & \\
\hline \multicolumn{5}{|l|}{ Mobility } \\
\hline Completely immobile & $42(47.2 \%)$ & $47(52.8 \%)$ & $6.55(2.54,16.93)^{* *}$ & \\
\hline Very limited & $13(9.3 \%)$ & $127(90.7 \%)$ & $0.75(0.27,2.11)$ & \\
\hline Slightly limited & $10(7 \%)$ & $133(93 \%)$ & $0.55(0.19,1.60)$ & \\
\hline No limitation & $6(12 \%)$ & $44(88 \%)$ & 1 & \\
\hline \multicolumn{5}{|l|}{ Nutrition } \\
\hline Very poor & $11(27.5 \%)$ & $29(72.5 \%)$ & $2.74(1.17,6.42)^{* *}$ & \\
\hline Probably inadequate & $42(17.9 \%)$ & $192(82.1 \%)$ & $1.58(0.87,2.87)^{*}$ & \\
\hline Adequate & $18(12.2 \%)$ & $130(87.8 \%)$ & 1 & \\
\hline \multicolumn{5}{|l|}{ Friction and shear } \\
\hline Problem & $26(48.1 \%)$ & $28(51.9 \%)$ & $13.54(6.13,29.9)^{* *}$ & $4.49(1.56,12.9)$ \\
\hline Potential problem & $33(18.2 \%)$ & $148(81.8 \%)$ & $3.25(1.62,6.52)^{* *}$ & $1.89(0.79,4.54)$ \\
\hline No apparent problem & $12(6.4 \%)$ & $175(93.6 \%)$ & 1 & 1 \\
\hline
\end{tabular}

NB: ${ }^{*} P \leq 0.2,{ }^{* *} P \leq 0.05$.

The logistic regression used backward LR for multivariate analysis.

On this finding, Braden subscales pressure ulcer risk assessment of sensory perception, activity, mobility, moisture, nutrition, and friction and shear were associated with development of pressure ulcer in binary logistic regression. A similar study was conducted in Sweden; these Braden scales were associated with the occurrence of pressure ulcer [9]; however, of the six Braden subscales, sensory perception and friction and shear were associated with pressure ulcer development in multiple logistic regression in this finding.

Patients with completely limited activity and who had moisture were liable to develop pressure ulcer. The presence of constant moisture and bedfast (completely limited activity) for long period of time facilitate skin laceration. This study also revealed the association between completely limited activity and moisture and pressure ulcer development in binary logistic regression. A similar study was conducted in Thailand, which revealed that occurrence of pressure ulcer was associated with the completely limited activity and presence of moisture [22]. However these two Braden subscales were not strongly associated with multiple logistic regressions in this investigation.

The major predictor of Braden subscale associated with developed pressure ulcer in hospitalized patients in this study was the problem of friction and shearing forces. When shear occurs, tissue layers slide over one another, blood vessels stretch and twist, and the microcirculation of the skin and subcutaneous tissue is disrupted. The present study investigated that the problem of friction and shearing was statistically significant and strongly associated with pressure ulcer development. This result was in agreement with the study conducted in Brazil [11]. The possible reason is due to the fact that friction and shearing problem lacerates skin forcefully.

Due to the fact that patients with completely limited sensory perception were liable to friction and shear problem, this finding revealed that highest prevalence of pressure ulcer was seen in patients with friction and shear problem. This is in line with the study done in Germany [24]. The possible reason might be that completely limited sensory perception patients cannot perform activities and change their position without assistant and they are sliding down from the bed.

Spastic muscles and paralysis increase the patient's vulnerability to pressure ulcers related to friction and shear. As the person slides down or is improperly pulled up in bed, friction resists this movement. Shear occurs when one layer of tissue slides over another, disrupting microcirculation of skin and subcutaneous tissue. This finding also investigated that friction and shearing force was strongly associated with the occurrence of pressure ulcer. This is in line with the study conducted in Thailand [20]. The reason is that mechanical forces contribute to pressure ulcer development.

In this study, it was revealed that the prevalence of pressure ulcer increased when hospitalization of patient increased. This implies that length of time was significantly associated with occurrence of pressure ulcer. This finding was in agreement with the study conducted in Sweden, more hospitalization of patients strongly associated with development of pressure ulcer [23]. This might be due to prolonged pressure and decrease of blood circulation in particular area.

Regarding hospitalization time, in this study, it was revealed that the prevalence of pressure ulcer increased with the increase of time of patient's stay in hospital. In multivariate analysis, the association between hospitalization time of more than 7 days and pressure ulcer occurrence was very strong. The development of pressure ulcer was strongly associated with long stay of patients in hospital. According to literature in Turkey pressure ulcers usually develop within the first two weeks of hospitalization [25]. This finding also investigated that majority of patients developed pressure ulcer staying in hospital for more than 20 days. When patients stay in hospital for long period of time, they will be exposed to hospital acquired infection and they will be susceptible to development of pressure ulcer. So that length of 
stay in hospital was strongly associated with the development of pressure ulcer. This finding was supported by the study conducted in Brazil [8]. The possible reason of association between length of stay in hospital and occurrence of pressure ulcer is that patients may not get appropriate nursing care and adequate nutrition and they deteriorate with concomitant disease.

Patients with sensory loss, impaired level of consciousness, or paralysis may not be aware of the discomfort associated with prolonged pressure on the skin and, therefore, may not change their position themselves to relieve the pressure. This prolonged pressure impedes blood flow, reducing nourishment of the skin and underlying tissues, despite the fact that in this finding slightly limited sensory perception was associated with occurrence of PU. This finding was in agreement with the study conducted in Thailand; pressure ulcers were most developed in patients who had slight limitation in sensory perception [22]. The possible reason might be that most of respondents participating in this study had slightly limited sensory perception.

This study had also some limitations. The main limitations of this study were that pressure ulcer was done through cross-sectional rather than prospective (follow-up) study, lack of standardized questionnaire related to this specific topic, and lack of literature in Ethiopia which makes it difficult to compare results.

\section{Conclusion}

The prevalence of pressure ulcer was high among hospitalized patients. Prolonged length of stay in hospital, problem of sensory perception, and friction and shearing forces were significantly associated with the presence of pressure ulcer. Patients who had stayed in hospital for more than twenty days and had problem in friction and shear were more liable to develop pressure ulcer. Majority of ulcer developed patients did not change their position by the nurse frequently.

\section{Appendix}

\section{Braden Scale Pressure Ulcer Risk Assessment}

Sensory Perception. Sensory perception measures the individual ability to feel and report discomfort.

(1) Completely Limited. The patient is unresponsive (does not moan, flinch, or grasp) to painful stimuli, due to diminished level of consciousness or sedation or limited ability to feel pain over most of the body.

(2) Very Limited. The patient responds only to painful stimuli, cannot communicate discomfort except by moaning or restlessness, or has a sensory impairment which limits the ability to feel pain or discomfort over $1 / 2$ of body.

(3) Slightly Limited. The patient responds to verbal commands but cannot always communicate discomfort or the need to be turned or has some sensory impairment which limits the ability to feel pain or discomfort in one or two extremities.

(4) No Impairment. The patient responds to verbal commands and has no sensory deficit which would limit the ability to feel or voice pain or discomfort.

Moisture. Moisture measures the degree to which the skin is exposed to moisture.

(1) Constantly Moist. The skin is kept moist almost constantly by perspiration, urine, and so forth; dampness is detected every time the patient is moved or turned.

(2) Very Moist. The skin is often but not always moist. Linen must be changed at least once a shift.

(3) Occasionally Moist. The skin is occasionally moist, requiring an extra linen change approximately once a day.

(4) Rarely Moist. The skin is usually dry; linen only requires changing at routine intervals.

Activity. This includes degree of physical activity.

(1) Bedfast. The patient is confined to bed.

(2) Chairfast. This includes severely limited ability to walk or nonexistent one. The patient cannot bear his/her own weight and/or must be assisted into chair or wheelchair.

(3) Walks Occasionally. The patient walks occasionally during day, but for very short distances, with or without assistance and spends the majority of each shift in bed or chair.

(4) Walks Frequently. The patient walks outside the room at least twice a day and inside the room at least once every 2 hours during waking hours.

Mobility. This includes the ability to change and control body position.

(1) Completely Immobile. The patient does not make even slight changes in his/her body or extremity position without assistance.

(2) Very Limited. The patient makes occasional slight changes in his/her body or extremity position but is unable to make frequent or significant changes independently.

(3) Slightly Limited. The patient makes frequent slight changes in his/her body or extremity position independently.

(4) No Limitation. The patient makes major and frequent changes in his/her position without assistance.

Nutrition. Nutrition reflects the food intake pattern of the assessed person, as well as liquid supplements. 
(1) Very Poor. The patient never eats a complete meal, rarely eats more than $1 / 3$ of any food offered, eats 2 servings or less of protein (meat or dairy products) per day, takes fluid poorly, does not take a liquid dietary supplement, or does not take any food by mouth and/or maintained on clear liquids or intravenous solutions for more than 5 days.

(2) Probably Inadequate. The patient rarely eats a complete meal and generally eats only about $1 / 2$ of any food offered. Protein intake includes only 3 servings of meat or dairy products per day. Occasionally the patient will take a dietary supplement or receives less than optimum amount of liquid diet or tube feeding.

(3) Adequate. The patient eats over half of most meals, eats a total of 4 servings of protein (meat, dairy products) per day, occasionally will refuse a meal but will usually take a supplement when offered, or is on a tube feeding.

Friction/Shear. Friction and shear assess the person's ability to keep the skin free from contact with the wrinkle area.

(1) Problem. The patient requires moderate to maximum assistance in moving. Complete lifting without sliding against sheets is impossible. The patient frequently slides down in bed or chair, requiring frequent repositioning with maximum assistance. Spasticity, contractures, or agitation leads to almost constant friction.

(2) Potential Problem. The patient moves feebly or requires minimum assistance. During a move skin probably slides to some extent against sheets, chair, restraints, or other devices. The patient maintains relatively good position in chair or bed most of time but occasionally slides down.

(3) No Apparent Problem. The patient moves in bed and in chair independently and has sufficient muscle strength to lift up completely during move and maintains good position in bed or chair.

\section{Conflict of Interests}

The authors declare that there is no conflict of interests regarding the publication of this paper.

\section{Authors' Contribution}

Haileyesus Gedamu wrote the proposal, participated in data collection, analyzed the data, and drafted the paper. Abdella Amano and Mignote Hailu approved the proposal with some revisions, participated in data analysis, and revised subsequent drafts of the paper. All authors read and approved the final paper. Abdella Amano and Mignote Hailu contributed equally to this work.

\section{Acknowledgments}

The authors are very grateful to the University of Gondar for the approval of the ethical clearance and Amhara Regional Health Bureau for its financial support. They would also like to thank all admitted patients who participated in this study for their commitment in responding to their interviews. Their gratitude also goes to supervisors, the data collectors, and the staff at the hospital.

\section{References}

[1] C. H. Lyder and E. A. Ayello, "Pressure ulcers: a patient safety issue," in Patient Safety and Quality: An Evidence-Based Handbook for Nurses, R. G. Hughes, Ed., chapter 12, Agency for Healthcare Research and Quality, Rockville, Md, USA, 2008.

[2] S. C. Smeltzer, B. G. Bare, J. L. Hinkle, and K. H. Cheever, Brunner and Suddarth's Text book of Medical-Surgical Nursing, Lippincott Williams \& Wilkins, London, UK, 12th edition.

[3] National Pressure Ulcer Advisory Panel and European Pressure Ulcer Advisory Panel, Prevention and Treatment of Pressure Ulcers: A Clinical Practice Guideline, European Pressure Ulcer Advisory Panel, Stockholm, Sweden, 2009.

[4] J. Kottner, K. Balzer, T. Dassen, and S. Heinze, "Pressure ulcers: a critical review of definitions and classifications," Ostomy Wound Management, vol. 55, no. 9, pp. 22-29, 2009.

[5] J. Anders, A. Heinemann, C. Leffmann, M. Leutenegger, F. Pröfener, and W. Von Renteln-Kruse, "Decubitus ulcers: pathophysiology and primary prevention," Deutsches Arzteblatt, vol. 107, no. 21, pp. 371-382, 2010.

[6] P. Lowthian, "The distinction between superficial pressure ulcers and moisture lesions.", Skinmed, vol. 6, no. 3, pp. 111-112, 2007.

[7] B. M. Bates-Jensen, H. E. McCreath, and V. Pongquan, "Subepidermal moisture is associated with early pressure ulcer damage in nursing home residents with dark skin tones: pilot findings," Journal of Wound, Ostomy and Continence Nursing, vol. 36, no. 3, pp. 277-284, 2009.

[8] E. S. M. Shahin, T. Dassen, and R. J. G. Halfens, "Pressure ulcer prevalence in intensive care patients: a cross-sectional study," Journal of Evaluation in Clinical Practice, vol. 14, no. 4, pp. 563$568,2008$.

[9] C. Vangilder, S. Amlung, P. Harrison, and S. Meyer, "Results of the 2008-2009 international pressure ulcer prevalence survey and a 3-Year, acute care, unit-specific analysis," Ostomy Wound Management, vol. 55, no. 11, pp. 39-45, 2009.

[10] S. D. Horn, P. Buerhaus, N. Bergstrom, and R. J. Smout, "RN staffing time and outcomes of long-stay nursing home residents," American Journal of Nursing, vol. 105, no. 11, pp. 5871, 2005.

[11] C. Iglesias, J. Nixon, G. Cranny et al., "Pressure relieving support surfaces (PRESSURE) trial: cost effectiveness analysis," British Medical Journal, vol. 332, no. 7555, pp. 1416-1418, 2006.

[12] S. Inui, Y. Konishi, Y. Yasui, T. Harada, and S. Itami, "Successful intervention for pressure ulcer by nutrition support team: a case report," Case Reports in Dermatology, vol. 2, no. 2, pp. 120-124, 2010.

[13] J. McGuinness, S. Persaud-Roberts, S. Marra et al., "How to reduce hospital-acquired pressure ulcers on a neuroscience unit with a skin and wound assessment team," Surgical Neurology International, vol. 3, article 138, 2012. 
[14] O. Assadian, JS. Oswald, R. Leisten et al., "Management of leg and pressure ulcer in hospitalized patients: direct costs are lower than expected," GMS Krankenhaushygiene Interdisziplinär, vol. 6, no. 1, 2011.

[15] J. M. F. Chacon, L. Blanes, B. Hochman, and L. M. Ferreira, "Prevalence of pressure ulcers among the elderly living in longstay institutions in São Paulo," Sao Paulo Medical Journal, vol. 127, no. 4, pp. 211-215, 2009.

[16] D. G. Inan and G. Öztunç, "Pressure ulcer prevalence in Turkey: a sample from a university hospital," Journal of Wound, Ostomy and Continence Nursing, vol. 39, no. 4, pp. 409-413, 2012.

[17] N. A. Lahmann, R. J. Halfens, and T. Dassen, "Prevalence of pressure ulcers in Germany," Journal of Clinical Nursing, vol. 14, no. 2, pp. 165-172, 2005.

[18] L. Gunningberg and N. A. Stotts, "Tracking quality over time: what do pressure ulcer data show?” International Journal for Quality in Health Care, vol. 20, no. 4, pp. 246-253, 2008.

[19] A. Capon, N. Pavoni, A. Mastromattei, and D. di Lallo, "Pressure ulcer risk in long-term units: prevalence and associated factors," Journal of Advanced Nursing, vol. 58, no. 3, pp. 263-272, 2007.

[20] C. Suttipong and S. Sindhu, "Predicting factors of pressure ulcers in older Thai stroke patients living in urban communities," Journal of Clinical Nursing, vol. 21, no. 3-4, pp. 372-379, 2012.

[21] S. E. Rich, M. Shardell, D. Margolis, and M. Baumgarten, "Pressure ulcer preventive device use among elderly patients early in the hospital stay," Nursing Research, vol. 58, no. 2, pp. 95-104, 2009.

[22] J. Black, C. Berke, and G. Urzendowski, "Pressure ulcer incidence and progression in critically ill subjects: influence of low air loss mattress versus a powered air pressure redistribution mattress," Journal of Wound Ostomy \& Continence Nursing, vol. 39, no. 3, pp. 267-273, 2012.

[23] L. Gunningberg, N. A. Stotts, and E. Idvall, "Hospital-acquired pressure ulcers in two Swedish County Councils: crosssectional data as the foundation for future quality improvement," International Wound Journal, vol. 8, no. 5, pp. 465-473, 2011.

[24] N. A. Lahmann and J. Kottner, "Relation between pressure, friction and pressure ulcer categories: a secondary data analysis of hospital patients using CHAID methods," International Journal of Nursing Studies, vol. 48, no. 12, pp. 1487-1494, 2011.

[25] S. Sayar, S. Turgut, H. Doğan et al., "Incidence of pressure ulcers in intensive care unit patients at risk according to the Waterlow scale and factors influencing the development of pressure ulcers," Journal of Clinical Nursing, vol. 18, no. 5, pp. 765-774, 2009. 


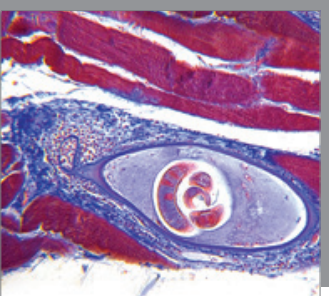

Gastroenterology

Research and Practice
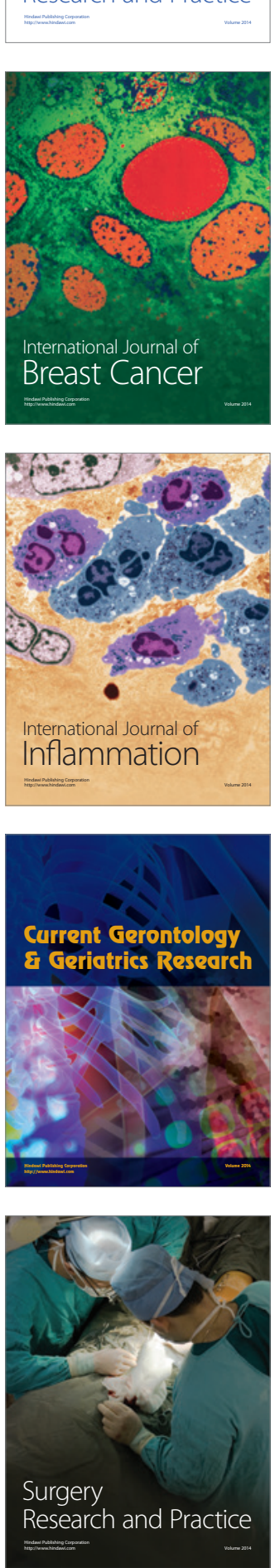

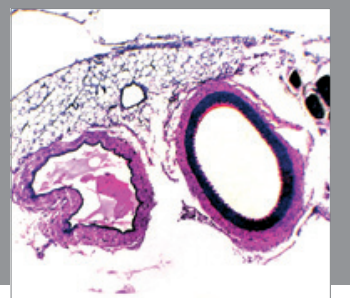

International Journal of Hypertension
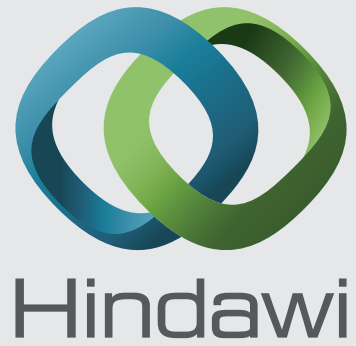

Submit your manuscripts at http://www.hindawi.com
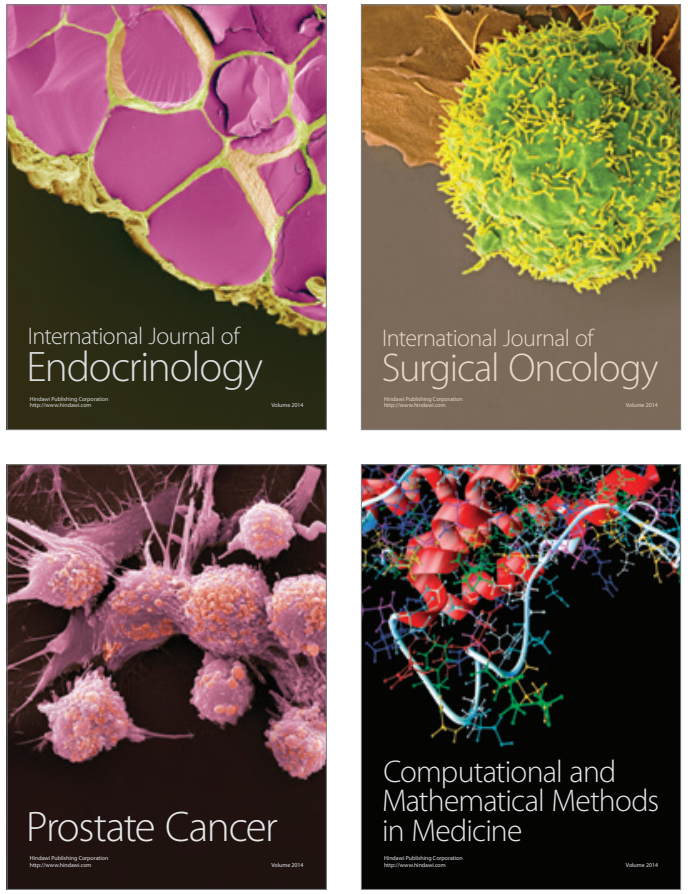
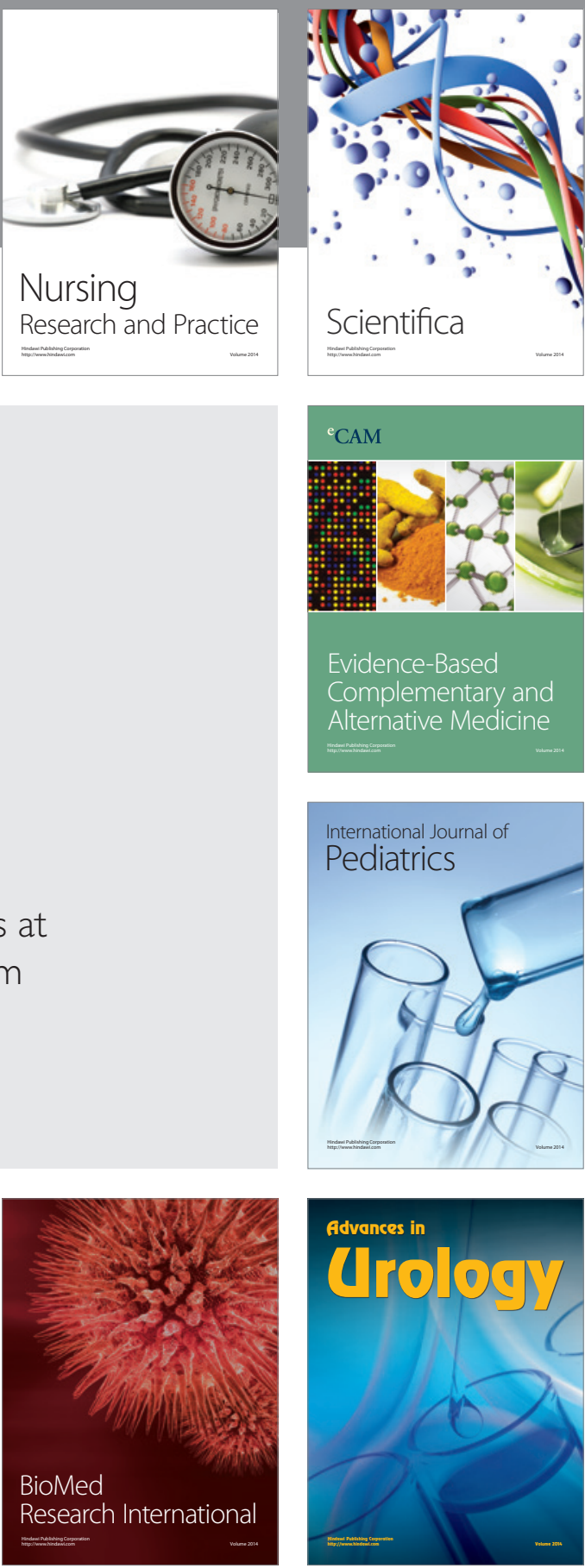

Nursing

Research and Practice

Scientifica

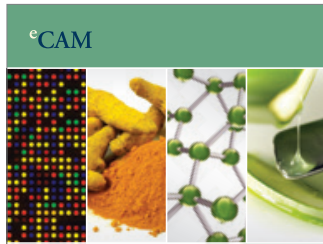

Evidence-Based

Complementary and Alternative Medicine
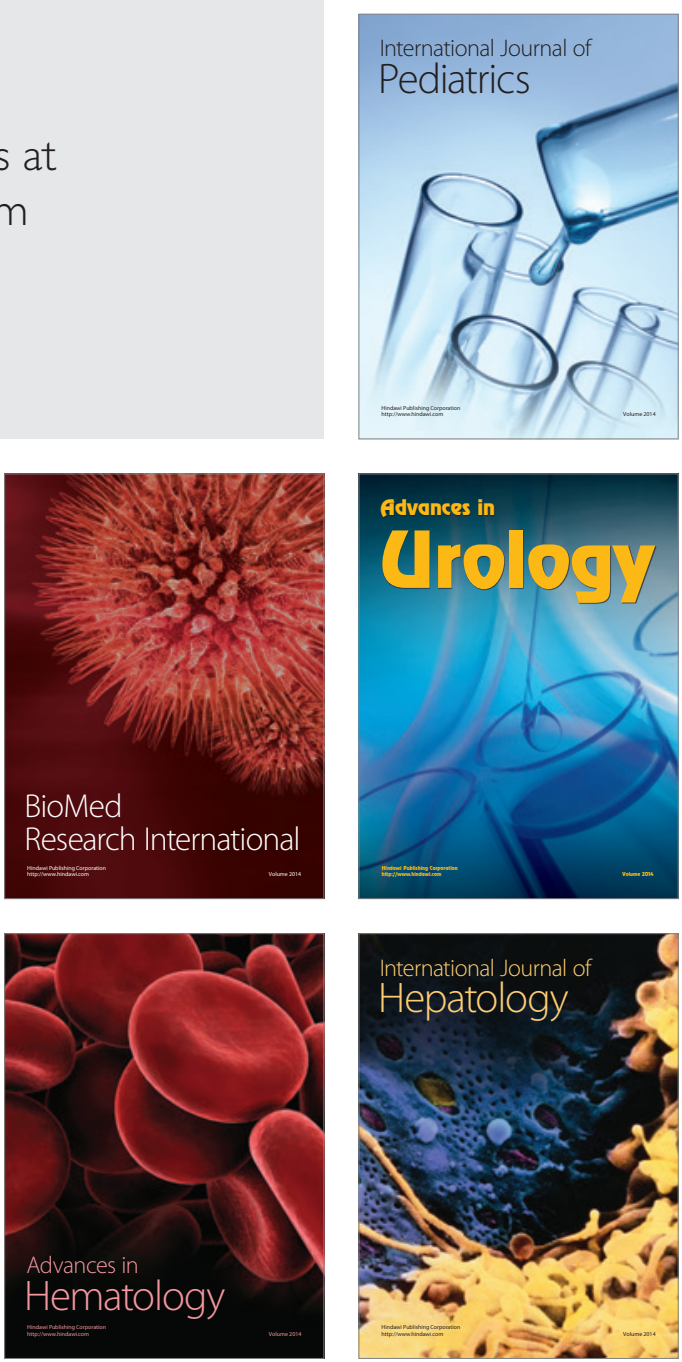